\title{
Effect of hatha yoga intervention on cardiovascular system in women after breast cancer surgery
}

\author{
DOI: https://doi.org/10.5114/pq.2021.105883
}

\author{
Tetiana Odynets ${ }^{1}$, Yuriy Briskin², Borys Dolinsky ${ }^{3}$, Iryna Osipova ${ }^{4}$, Tetiana Pasichna ${ }^{5}$, Anzhelika Yefremova ${ }^{6}$ \\ ${ }^{1}$ Department of Physical Rehabilitation, Khortytsia National Academy, Zaporizhzhya, Ukraine \\ ${ }^{2}$ Department of Theory of Sport and Physical Culture, Lviv State University of Physical Culture, Lviv, Ukraine \\ ${ }^{3}$ Department of Gymnastics and Martial Arts, South Ukrainian National Pedagogical University named after \\ K.D. Ushynsky, Odessa, Ukraine \\ ${ }^{4}$ Department of Theory and Methods of Physical Culture and Sports Disciplines, South Ukrainian National Pedagogical \\ University named after K.D. Ushynsky, Odessa, Ukraine \\ ${ }^{5}$ National Technical University of Ukraine "Igor Sikorsky Kyiv Polytechnic Institute", Kyiv, Ukraine \\ ${ }^{6}$ Department of Physical Education and Sport, Ukrainian State University of Railway Transport, Kharkiv, Ukraine
}

Abstract

Introduction. The aim of this study was to investigate and compare the effects of 2 different exercise regimens on cardiovascular fitness in women with breast cancer.

Methods. A total of 110 women consented to take part in the study but only 102 met the inclusion criteria and were involved (8 patients did not meet the research criteria and were excluded); 95 women completed the interventions and were included in the final analysis. The patients' mean age was $57.53 \pm 1.92$ years for group A and $58.00 \pm 1.27$ years for group B. The participants were randomly assigned to 2 groups. Group A $(n=48)$ received hatha yoga intervention and group B $(n=47)$ received Pilates intervention for 3 months. Impedance cardiography was used to measure pre- and post-intervention functional capacity of the cardiovascular system.

Results. Post-intervention impact was observed for both intervention approaches, but better improvement was noted in the group of hatha yoga than that of Pilates. The actual values of stroke volume and left ventricular power were significantly higher in group A compared with group B by $6.05 \mathrm{ml} /$ beat $(p<0.05)$ and $0.19 \mathrm{~W}(p<0.05)$, respectively; the relative values were correspondingly better by $6.22 \%(p<0.05)$ and $10.71 \%(p<0.05)$.

Conclusions. Hatha yoga and Pilates interventions are both effective in improving cardiovascular function, but hatha yoga turns out more beneficial.

Key words: breast cancer, hatha yoga, cardiovascular system, Pilates, physical intervention

\section{Introduction}

Cardiovascular disease is the most common cause of mortality in patients who have survived cancer [1, 2]. Most studies have shown a high frequency of cardiovascular side effects after breast cancer treatment [3, 4]. This circumstance leads to a variety of interventions designed to improve the quality of life of patients with breast cancer [5-10].

Women commonly experience cardiotoxicity, and issues related to maximal oxygen uptake, cardiovascular endurance, and respiratory function [11-13]. Using radiation therapy in the chest $[14,15]$ reduces the adaptive capacity of the cardiovascular system, which is confirmed by a significant increase in tachycardia and a decrease in heart rate variability [16]. Also, a small effect on the left ventricle diastolic function is observed.

Post-treatment trophic disorders occur as a result of radiation, surgery, toxic tissue damage, vascular compression (lymph, blood), and nerve compression. In this way, low cardiovascular endurance and adaptive capacity, as well as functional disorders are common problems of these patients and might be important targets for yoga intervention [4, 17-20].

The results of previous research underline the significant role of different interventions in improving functional capacity of the cardiovascular system in breast cancer patients. These interventions include aerobic exercises [10, 21-23], water exercises [24], yoga exercises [25], and combined aerobic and resistance exercise programs [11, 26]. Nevertheless, previous studies have principally focused on the efficacy of yoga therapy in reducing fatigue, depression, and cancer-related lymphoedema in women suffering from breast cancer [27-29].

Thus, the rehabilitation of women with this diagnosis has a very high priority, since the evolution of functionally sparing operations does not exclude the need for individualized intervention. In addition, chemotherapy applied along with radiation therapy increases the number of treatment-induced problems that patients experience over a long period [1, 3], which necessitates the development of differentiated physical rehabilitation aimed at preventing post-treatment complications and improving the functional state of the cardiovascular system.

The assumed hypothesis here was that hatha yoga intervention might have a positive effect on cardiorespiratory fitness in women after breast cancer surgery. The study was conducted to investigate and compare the effects of 2 different exercise regimens on cardiovascular fitness in women with breast cancer.

Correspondence address: Tetiana Odynets, Department of Physical Rehabilitation, Khortytsia National Academy, 59 Naukove Mistechko Str., 69017, Zaporizhzhya, Ukraine, e-mail: tatyana01121985@gmail.com 


\section{Subjects and methods}

A total of 110 women consented to take part in the study but only 102 met the inclusion criteria and were involved (8 patients did not meet the research criteria and were excluded). Overall, 95 women completed the interventions and were included in the final analysis (Figure 1).

Comprehensive demographic and clinical characteristics of the participants are shown in Table 1. The women were randomized by using sequentially numbered, opaque sealed envelopes. The randomization was performed by an independent person via random numbers generated in Microsoft Excel. An independent person who was separate from the assessment and recruitment of the patients opened the envelopes. The participants' mean age was $57.53 \pm 1.92$ years for group $A$ (hatha yoga) and $58.00 \pm 1.27$ years for group $B$ (Pilates). There were no significant differences in the baseline cardiovascular parameters between the groups $(p>0.05)$. The inclusion criteria were as follows: Ukrainian individuals aged between 55 and 60 years, I-II stages of the tumour; the average time after breast cancer surgery (Madden mastectomy) ranged between 3 and 4 weeks. The exclusion criteria involved cognitive deficiency or psychiatric disease, bilateral mastectomy, heart failure, stage III tumour, refusal to participate. Impedance cardiography was used to measure pre- and post-intervention cardiovascular function. The independent researcher who administered the impedance cardiography was blinded to the group assignment of the participants. Overall, 95 women completed the intervention and were included in the final analysis.

The participants of group A and group B performed relevant programs 3 times per week for 3 months. The hatha yoga and Pilates intervention sessions lasted 60 minutes. Exercise intensity was individualized for the patients and varied from $50 \%$ to $60 \%$ of heart rate reserve. Both interventions took place at the Zaporizhzhya Regional Cancer Centre and

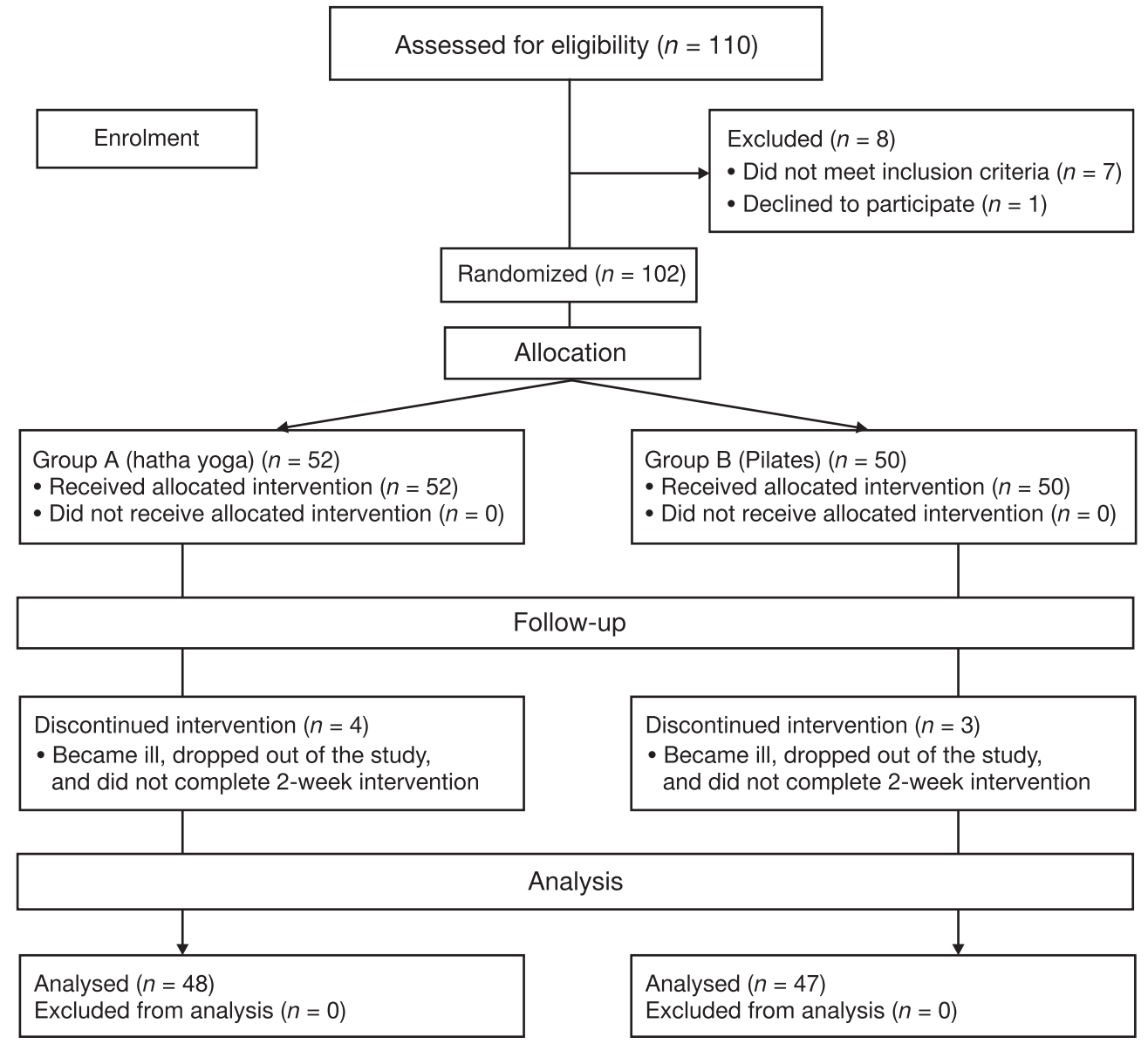

Figure 1. CONSORT flow diagram of the study

Table 1. Demographic and clinical characteristics of the participants

\begin{tabular}{|c|c|c|c|c|}
\hline \multirow{2}{*}{\multicolumn{2}{|c|}{ Characteristics }} & \multicolumn{2}{|c|}{ Groups } & \multirow{2}{*}{$p$} \\
\hline & & $\mathrm{A}(n=48)$ & $\mathrm{B}(n=47)$ & \\
\hline \multicolumn{2}{|c|}{ Age, years $(M \pm S D)$} & $57.53 \pm 1.92$ & $58.00 \pm 1.27$ & $>0.05$ \\
\hline \multirow{2}{*}{ Race } & White, n (\%) & $46(96)$ & $45(96)$ & $>0.05$ \\
\hline & Black, n (\%) & $2(4)$ & $2(4)$ & $>0.05$ \\
\hline \multicolumn{2}{|c|}{ Body mass index, $\mathrm{kg} / \mathrm{m}^{2}(M \pm S D)$} & $24.23 \pm 0.38$ & $24.25 \pm 0.43$ & $>0.05$ \\
\hline \multicolumn{2}{|c|}{ Time since surgery treatment completion, weeks $(\mathrm{M} \pm \mathrm{SD})$} & $3.23 \pm 1.17$ & $3.25 \pm 1.19$ & $>0.05$ \\
\hline Cancer stage & $1, n(\%)$ & $8(17)$ & 9 (19) & $>0.05$ \\
\hline
\end{tabular}


were performed by the same certified yoga and Pilates therapist.

Hatha yoga application was conducted 3 times a week for 12 weeks. Each session consisted of several continuous poses (static, dynamic, stato-dynamic, relaxing, and respiratory) that were based on the participants' individual baseline functional capacity of the cardiovascular system. The yoga intervention consisted of breathing exercises (10 min), asanas in standing, sitting, lying positions (40 $\mathrm{min})$, and relaxation exercises in lying position (10 min). The patients adhered to the following recommendations throughout their hatha yoga sessions:

1. Each hatha yoga session began with the dynamic performance of joint gymnastics exercises that increased the range of motion in the joints and prepared them for static loading.

2. Complex application of asanas and breathing exercises occurred in one session, as well as their combinations from various starting points for the full involvement of all muscle groups in the work.

3. The implementation of dynamic and static respiratory actions was well harmonized, which allowed to achieve full coordination of movements and capabilities for a long time to maintain physical activity in an optimal pulse mode.

4. At the beginning of the asanas learning, breath holding and closing of the eyes were avoided; after mastering the good technique, the women were recommended to close their eyes to provide a better concentration of attention on movements and gradually increase the time of posture holding.

5. In the final part of the session, the women achieved muscular and mental relaxation by focusing on their feelings in one of the asanas (Shavasana, Makarasana, or Balasana).

6 . It is advisable to combine the performance of several asanas without rest breaks into stato-dynamic complexes to maintain a predetermined heart rate; passive rest breaks were performed between Shavasana or Makarasana if necessary.

7. To overcome the obstructive type of respiratory dysfunction, static pranayama was used to change the phases of the respiratory cycle (time of inhalation and exhalation); with alternate change of the type of breathing (elements of full breathing); with forced exhalations due to abdominal and diaphragm muscles (Kapalabhati, Bhastrika breathing); with delayed breathing after prolonged exhalation (Rechaka, Shunyaka, rhythmic breathing); with increasing strength and endurance of expiratory respiratory muscles (Uddiyana Bandha, Uddiyana Bandha Kriya, etc.).

8. To regulate the activity of the autonomic nervous system, the women focused on the duration of the respiratory cycle phases, respiratory retardation, and stimulation of breathing of air through the corresponding nostrils: to increase the activity of the parasympathetic department to make prolonged non-forced exhalation, delay after exhalation and asymmetric breathing; to increase the activity of the sympathetic department - on forced inhalation and exhalation through the right nostril, delay after inhalation.

9. Inverted asanas were carefully used for women who had high blood pressure. Values of the blood pressure ranged from $120 / 80$ to $150 / 90$ in the breast cancer patients, but we did not use inverted asanas for women with blood pressure exceeding 140/90.

Group B participants performed a Pilates program that included Pilates matwork exercises (50\%), Power Pilates (20\%), Pilates ball (20\%), and Pilates stretch (10\%). The main purpose of Pilates matwork exercises was to teach the women safe and rational techniques of performing basic exercises, breathing properly, and focusing on the movements per- formed. Exercise intensity was related to the functional capacity of the cardiovascular system in the women after breast cancer surgery.

Using impedance cardiography, the following parameters were evaluated: stroke volume (ml/beat), cardiac output $(\mathrm{l} / \mathrm{min})$, stroke index $\left(\mathrm{ml} / \mathrm{beat} / \mathrm{m}^{2}\right)$, systemic vascular resistance $\left(\right.$ dyn $\left.\cdot \mathrm{s} / \mathrm{cm}^{5}\right)$, left ventricular work ( $\mathrm{gm}-\mathrm{m} /$ beat), left ventricular power $(\mathrm{W})$.

The obtained data were analysed with the Statistical Package for the Social Sciences (SPSS) computer program. The Shapiro-Wilk test was preliminarily completed to spot the normal distribution of data. Dependent t-test was used to compare pre- and post-treatment cardiovascular changes for each group. Independent t-tests served to compare postintervention cardiovascular parameters between group $A$ and group B.

\section{Ethical approval}

The research related to human use has complied with all the relevant national regulations and institutional policies, has followed the tenets of the Declaration of Helsinki, and has been approved by the ethical committee of Khortytsia National Academy.

\section{Informed consent}

Informed consent has been obtained from all individuals included in this study.

\section{Results}

It was identified that hatha yoga and Pilates positively influenced cardiovascular functions in patients with breast cancer. As presented in Table 2, the dependent and independent t-test analysis revealed that in both groups there was a significant increase in the functional state of the cardiovascular system.

Post-intervention impact was observed for both intervention approaches, but better improvement was noted in the group of hatha yoga than that of Pilates $(p<0.05)$.

After the 3-month hatha yoga intervention, a significant increase was observed in group $A$ : in actual stroke volume by $6.05 \mathrm{ml} /$ beat $(p<0.01)$, in stroke index by $3.84 \mathrm{ml} / \mathrm{beat} / \mathrm{m}^{2}$ $(p<0.01)$, in left ventricular work by $0.41 \mathrm{gm}-\mathrm{m} /$ beat $(p<0.05)$, and in left ventricular power by $0.27 \mathrm{~W}(p<0.05)$. The predicted values of stroke volume and left ventricular power improved significantly in patients of group A by $8.88 \%$ ( $p<$ $0.05)$ and $11.22 \%(p<0.05)$, respectively. It is also worth noting a decrease in the total peripheral vascular resistance in both groups: by $246.20 \mathrm{dyn} \cdot \mathrm{s} / \mathrm{cm}^{5}(p<0.05)$ in group $A$ and by $26.10 \mathrm{dyn} \cdot \mathrm{s} / \mathrm{cm}^{5}(p>0.05)$ in group $\mathrm{B}$.

Applying the Pilates intervention in group $B$ resulted only in a significant improvement of stroke volume by $3.92 \mathrm{ml} /$ beat $(p<0.05)$ and stroke index by $2.54 \mathrm{ml} / \mathrm{beat} / \mathrm{m}^{2}(p<0.05)$.

A comparison of post-intervention score averages of the cardiovascular function between the groups showed advantages of hatha yoga compared with Pilates for some indicators (Table 2). The actual values of stroke volume and left ventricular power were significantly higher in group A compared with group B participants: by $6.05 \mathrm{ml} /$ beat $(p<0.05)$ and by $0.19 \mathrm{~W}(p<0.05)$, respectively; the relative values were correspondingly better by $6.22 \%(p<0.05)$ and $10.71 \%$ $(p<0.05)$. 
Table 2. The evolution of cardiovascular function (mean \pm error of mean) measured by impedance cardiography in the studied groups

\begin{tabular}{|c|c|c|c|c|c|c|c|}
\hline \multirow{2}{*}{\multicolumn{2}{|c|}{ Indicator }} & \multicolumn{3}{|c|}{ Group A $(n=48)$} & \multicolumn{3}{|c|}{ Group B $(n=47)$} \\
\hline & & \multirow{2}{*}{$\begin{array}{l}\text { Beginning } \\
45.88 \pm 1.51\end{array}$} & \multirow{2}{*}{$\begin{array}{c}\begin{array}{c}\text { 3-month } \\
\text { intervention }\end{array} \\
55.74 \pm 1.72^{*}\end{array}$} & \multirow{2}{*}{$\begin{array}{c}p \\
<0.01\end{array}$} & \multirow{2}{*}{$\begin{array}{l}\text { Beginning } \\
45.77 \pm 1.58\end{array}$} & \multirow{2}{*}{$\begin{array}{c}\begin{array}{c}\text { 3-month } \\
\text { intervention }\end{array} \\
49.69 \pm 1.86\end{array}$} & \multirow{2}{*}{$\begin{array}{c}p \\
<0.05\end{array}$} \\
\hline & Actual & & & & & & \\
\hline (1) & $\%$ of predicted & $73.07 \pm 2.14$ & $81.95 \pm 1.95^{\star}$ & $<0.05$ & $72.30 \pm 1.61$ & $75.73 \pm 1.72$ & $>0.05$ \\
\hline \multicolumn{2}{|l|}{ Stroke index, $\mathrm{ml} / \mathrm{beat} / \mathrm{m}^{2}$} & $26.39 \pm 0.99$ & $30.23 \pm 1.11$ & $<0.01$ & $26.11 \pm 0.62$ & $28.65 \pm 1.01$ & $<0.05$ \\
\hline \multicolumn{2}{|l|}{ Cardiac output, I/min } & $3.34 \pm 0.10$ & $3.51 \pm 0.10$ & $>0.05$ & $3.36 \pm 0.08$ & $3.50 \pm 0.12$ & $>0.05$ \\
\hline \multirow{2}{*}{$\begin{array}{l}\text { Systemic vascular } \\
\text { resistance, dyn } \cdot \mathrm{s} / \mathrm{cm}^{5}\end{array}$} & Actual & $2151.27 \pm 63.73$ & $1905.07 \pm 60.13^{*}$ & $<0.05$ & $2107.06 \pm 57.47$ & $2080.96 \pm 51.78$ & $>0.05$ \\
\hline & $\%$ of predicted & $134.47 \pm 4.21$ & $117.72 \pm 3.44^{*}$ & $<0.01$ & $131.16 \pm 3.22$ & $127.49 \pm 3.31$ & $>0.05$ \\
\hline \multirow{2}{*}{$\begin{array}{l}\text { Left ventricular work, } \\
\text { gm-m/beat }\end{array}$} & Actual & $4.02 \pm 0.11$ & $4.43 \pm 0.11$ & $<0.05$ & $4.12 \pm 0.11$ & $4.21 \pm 0.15$ & $>0.05$ \\
\hline & $\%$ of predicted & $74.25 \pm 2.10$ & $79.27 \pm 1.31$ & $<0.05$ & $75.06 \pm 1.87$ & $76.43 \pm 2.79$ & $>0.05$ \\
\hline \multirow{2}{*}{$\begin{array}{l}\text { Left ventricular power, } \\
\text { W }\end{array}$} & Actual & $2.07 \pm 0.08$ & $2.34 \pm 0.06^{\star}$ & $<0.05$ & $2.14 \pm 0.09$ & $2.15 \pm 0.06$ & $>0.05$ \\
\hline & $\%$ of predicted & $78.22 \pm 2.60$ & $89.97 \pm 2.97^{*}$ & $<0.01$ & $78.13 \pm 2.77$ & $79.26 \pm 2.94$ & $>0.05$ \\
\hline
\end{tabular}

${ }^{*} p<0.05$ for comparing the data between group $\mathrm{A}$ and group $\mathrm{B}$

\section{Discussion}

The present study was conducted to evaluate the impact of hatha yoga intervention on the cardiovascular system in patients after breast cancer surgery. Most previous yoga programs for patients with breast cancer have been performed to reduce cancer treatment-related symptoms such as fatigue, heart rate variability, lymphoedema, depression, anxiety, and poor quality of life [17-19, 30]. Some previous studies have identified that yoga considerably impacts on cardiorespiratory fitness and strength in healthy adults [31-33], but hatha yoga effect on functional capacity of the cardiovascular system in breast cancer Ukrainian patients has not been reported. Recent evidence suggests that combined aerobic and resistance exercises [11, 34-36], combined exercise plus diet program [37], and a water program [24, 38] contribute to an improvement in cardiorespiratory fitness in breast cancer survivors.

Previous studies of water therapy conducted by Odynets et al. [24, 38] involved an intervention of 3 times a week for 3 months and resulted in more significant improvements in cardiac output, stroke index, systemic vascular resistance, left ventricular work, and respiratory function compared with a Pilates program in women after breast cancer therapy. However, the average time after surgery was about 5 months: significantly longer than the time presented in the current study. A combined exercise plus diet program described by Okumatsu et al. [37] was effective to improve relative and absolute maximal oxygen uptake in breast cancer patients, but the inclusion criteria involved a period of at least 1 year after surgery. This circumstance makes it difficult to provide comparisons with our results.

The current results demonstrated significant positive effects of the hatha yoga intervention on increasing stroke volume, stroke index, left ventricular work, and left ventricular power. Moreover, the 3-month yoga classes led to a significant decrease in peripheral vascular resistance, which is an important predictor of high blood pressure. These findings might be particularly important for women with low capacity to participate in traditional aerobic or resistance programs. The results of this research agree with those of other studies which suggest that yoga exercises are a safe and effective intervention for patients with breast cancer.
The current study has several notable strengths, which include a complex application of asanas and breathing exercises in accordance with the type of respiratory and autonomic dysfunction. To regulate the activity of the autonomic nervous system, emphasis was placed on the duration of the respiratory cycle phases, respiratory retardation, and stimulation of breathing through the corresponding nostrils. To increase the activity of the parasympathetic department, we focused on prolonged non-forced exhalation through the left nostril and delay after exhalation; to increase the activity of the sympathetic one - on forced inhalation and exhalation through the right nostril, delay after inhalation. Different asanas were performed in standing, sitting, and lying positions.

It is planned that next research will be aimed at determining the effectiveness of a hatha yoga intervention on improving quality of life in women after Madden mastectomy.

\section{Limitations}

The limitations of this study comprise a homogeneous population and a limited number of participants.

\section{Conclusions}

In the face of these results, we consider that the hatha yoga intervention was more effective, with a favourable impact on functional capacity of the cardiovascular system in women after breast cancer surgery. The actual values of stroke volume and left ventricular power were significantly higher in group A compared with group B by $6.05 \mathrm{ml} /$ beat $(p<0.05)$ and $0.19 \mathrm{~W}(p<0.05)$, respectively; the relative values were correspondingly better by $6.22 \%(p<0.05)$ and $10.71 \%(p<0.05)$.

\section{Disclosure statement}

No author has any financial interest or received any financial benefit from this research.

\section{Conflict of interest}

The authors state no conflict of interest. 


\section{References}

1. Jones LW, Courneya KS, Mackey JR, Muss HB, Pituskin EN, Scott JM, et al. Cardiopulmonary function and age-related decline across the breast cancer survivorship continuum. J Clin Oncol. 2012;30(20):2530-2537; doi: 10.1200/JCO.2011.39.9014.

2. Valachis A, Nilsson C. Cardiac risk in the treatment of breast cancer: assessment and management. Breast Cancer. 2015;7:21-35; doi: 10.2147/BCTT.S47227.

3. Hooning MJ, Botma A, Aleman BM, Baaijens MHA, Bartelink $\mathrm{H}$, Klijn JGM, et al. Long-term risk of cardiovascular disease in 10-year survivors of breast cancer. J Natl Cancer Inst. 2007;99(5):365-375; doi: 10.1093/ jnci/djk064.

4. Xie Y, Collins WJ, Audeh MW, Shiao SL, Gottlieb RA, Goodman MT, et al. Breast cancer survivorship and cardiovascular disease: emerging approaches in cardiooncology. Curr Treat Options Cardiovasc Med. 2015; 17(12):60; doi: 10.1007/s11936-015-0421-y.

5. Culos-Reed SN, Carlson LE, Daroux LM, Hately-AIdous S. A pilot study of yoga for breast cancer survivors: physical and psychological benefits. Psychooncology. 2006;15(10):891-897; doi: 10.1002/pon.1021.

6. Dangi AA, Aurangabadkar SK, Deo MV. Effect of a structured yoga program on fatigue, depression, cardiorespiratory fitness, and quality of life in a postmenopausal breast cancer survivor. Int J Yoga. 2018;11(3):255257; doi: 10.4103/ijoy.IJOY_61_17.

7. Keays KS, Harris SR, Lucyshyn JM, Maclntyre DL. Effects of Pilates exercises on shoulder range of motion, pain, mood, and upper-extremity function in women living with breast cancer: a pilot study. Phys Ther. 2008; 88(4):494-510; doi: 10.2522/ptj.20070099.

8. Olsson Möller U, Beck I, Rydén L, Malmström M. A comprehensive approach to rehabilitation interventions following breast cancer treatment - a systematic review of systematic reviews. BMC Cancer. 2019;19(1):472; doi: 10.1186/s12885-019-5648-7.

9. Peppone LJ, Janelsins MC, Kamen C, Mohile SG, Sprod LK, Gewandter JS, et al. The effect of YOCAS ${ }^{\circledR}$ yoga for musculoskeletal symptoms among breast cancer survivors on hormonal therapy. Breast Cancer Res Treat. 2015;150(3):597-604; doi: 10.1007/s10549-0153351-1.

10. Kim C-J, Kang D-H, Park J-W. A meta-analysis of aerobic exercise interventions for women with breast cancer. West J Nurs Res. 2009;31(4):437-461; doi: 10.1177/ 0193945908328473.

11. Aweto HA, Akinbo SRA, Olawale OA. Effects of combined aerobic and stretching exercises on the cardiopulmonary parameters of premenopausal and postmenopausal breast cancer survivors. Nig Q J Hosp Med. 2015; 25(3):177-183.

12. Odynets T, Briskin Y, Pityn M. Effect of individualized physical rehabilitation programs on respiratory function in women with post-mastectomy syndrome. Physiother Theory Pract. 2019;35(5):419-426; doi: 10.1080/09593 985.2018.1444117.

13. Odynets T, Briskin Y. Effect of individualised physical rehabilitation programmes on the functional state of the cardiovascular system in women with post-mastectomy syndrome. Int J Ther Rehabil. 2019;26(2):1-10; doi: 10.12968.ijtr.2018.0003.

14. Cueva JF, Antolín S, Calvo L, Fernández I, Ramos M, de Paz L, et al. Galician consensus on management of cardiotoxicity in breast cancer: risk factors, prevention, and early intervention. Clin Transl Oncol. 2017;19(9): 1067-1078; doi: 10.1007/s12094-017-1648-8.

15. Chandwani KD, Perkins G, Nagendra HR, Raghuram NV, Spelman A, Nagarathna R, et al. Randomized, controlled trial of yoga in women with breast cancer undergoing radiotherapy. J Clin Oncol. 2014;32(10):1058-1065; doi: 10.1200/JCO.2012.48.2752.

16. Guo Y, Koshy S, Hui D, Palmer JL, Shin K, Bozkurt M, et al. Prognostic value of heart rate variability in patients with cancer. J Clin Neurophysiol. 2015;32(6):516-520; doi: 10.1097/WNP.0000000000000210.

17. Harder H, Parlour L, Jenkins V. Randomised controlled trials of yoga interventions for women with breast cancer: a systematic literature review. Support Care Cancer. 2012; 20(12):3055-3064; doi: 10.1007/s00520-012-1611-8.

18. Kiecolt-Glaser JK, Bennett JM, Andridge R, Peng J, Shapiro CL, Malarkey WB, et al. Yoga's impact on inflammation, mood, and fatigue in breast cancer survivors: a randomized controlled trial. J Clin Oncol. 2014;32(10): 1040-1049; doi: 10.1200/JCO.2013.51.8860.

19. Buffart LM, van Uffelen JGZ, Riphagen II, Brug J, van Mechelen W, Brown WJ, et al. Physical and psychosocial benefits of yoga in cancer patients and survivors, a systematic review and meta-analysis of randomized controlled trials. BMC Cancer. 2012;12(1):559; doi: 10.1186/ 1471-2407-12-559.

20. Carson JW, Carson KM, Olsen MK, Sanders L, Porter LS. Mindful Yoga for women with metastatic breast cancer: design of a randomized controlled trial. BMC Complement Altern Med. 2017;17(1):153; doi: 10.1186/s12906-0171672-9.

21. Courneya KS, Segal RJ, Mackey JR, Gelmon K, Reid RD, Friedenreich $\mathrm{CM}$, et. al. Effects of aerobic and resistance exercise in breast cancer patients receiving adjuvant chemotherapy: a multicenter randomized controlled trial. J Clin Oncol. 2007;25(28):4396-4404.

22. Dolan LB, Gelmon K, Courneya KS, Mackey JR, Segal RJ, Lane $\mathrm{K}$, et al. Hemoglobin and aerobic fitness changes with supervised exercise training in breast cancer patients receiving chemotherapy. Cancer Epidemiol Biomarkers Prev. 2010;19(11):2826-2832; doi: 10.1158/ 1055-9965.EPI-10-0521.

23. Fairman CM, Focht BC, Lucas AR, Lustberg MB. Effects of exercise interventions during different treatments in breast cancer. J Community Support Oncol. 2016;14(5): 200-209; doi: 10.12788/jcso.0225.

24. Odynets T, Briskin Y, Zakharina I, Yefremova A. Influence of a water physical rehabilitation program on the hemodynamic parameters in breast cancer survivors. Physiother Quart. 2019;27(2):6-10; doi: 10.5114/pq. 2019.84267.

25. Hughes DC, Darby N, Gonzalez K, Boggess T, Morris RM, Ramirez AG. Effect of a six month yoga exercise intervention on fitness outcomes for breast cancer survivors. Physiother Theory Pract. 2015;31(7):451-460; doi: 10.3109/09593985.2015.1037409.

26. Travier N, Velthuis MJ, Steins Bisschop CN, van den Buijs B, Monninkhof EM, Backx F, et al. Effects of an 18-week exercise programme started early during breast cancer treatment: a randomised controlled trial. BMC Med. 2015;13:121; doi: 10.1186/s12916-015-0362-z.

27. Danhauer SC, Addington EL, Cohen L, Sohl SJ, Van Puymbroeck M, Albinati NK, et al. Yoga for symptom management in oncology: a review of the evidence base and future directions for research. Cancer. 2019;125(12): 1979-1989; doi: 10.1002/cncr.31979. 
28. Loudon A, Barnett T, Williams A. Yoga, breast cancer-related lymphoedema and well-being: a descriptive report of women's participation in a clinical trial. J Clin Nurs. 2017;26(23-24):4685-4695; doi: 10.1111/jocn.13819.

29. Sadja J, Mills PJ. Effects of yoga interventions on fatigue in cancer patients and survivors: a systematic review of randomized controlled trials. Explore. 2013;9(4):232243; doi: 10.1016/j.explore.2013.04.005.

30. Odynets T, Briskin Y, Todorova V, Tyshchenko V, Bondarenko $\mathrm{O}$. Effect of yoga in the modulation of heart rate variability in patients with breast cancer. Adv Rehabil. 2019;33(4):5-11; doi: 10.5114/areh.2019.89821.

31. Gaurav V. Effects of hatha yoga training on the healthrelated physical fitness. Int J Sports Sci Eng. 2011;5(3): 169-173.

32. Nivethitha L, Mooventhan A, Manjunath NK. Effects of various prānāyāma on cardiovascular and autonomic variables. Anc Sci Life. 2016;36(2):72-77; doi: 10.4103/ asl.ASL_178_16.

33. Tran MD, Holly RG, Lashbrook J, Amsterdam EA. Effects of hatha yoga practice on the health-related aspects of physical fitness. Prev Cardiol. 2001;4(4):165-170; doi: 10.1111/j.1520-037x.2001.00542.x.

34. Dolan LB, Barry D, Petrella T, Davey L, Minnes A, Yantzi $A$, et al. The cardiac rehabilitation model improves fitness, quality of life, and depression in breast cancer survivors. J Cardiopulm Rehabil Prev. 2018;38(4):246-252; doi: 10.1097/HCR.0000000000000256.

35. Dias Reis A, Silva Garcia JB, Rodrigues Diniz R, SilvaFilho AC, Dias CJ, Leite RD, et al. Effect of exercise training and detraining in autonomic modulation and cardiorespiratory fitness in breast cancer survivors. J Sports Med Phys Fitness. 2017;57(7-8):1062-1068; doi: 10.23736/ S0022-4707.17.07012-8.

36. Kulik-Parobczy I. Evaluation of the effectiveness of physiotherapy in patients after oncological breast cancer treatment based on spirometric indicators. Contemp Oncol. 2019;23(1):47-51; doi: 10.5114/wo.2019.82929.

37. Okumatsu K, Tsujimoto T, Wakaba K, Seki A, Kotake R, Yamauchi T, et al. Effects of a combined exercise plus diet program on cardiorespiratory fitness of breast cancer patients. Breast Cancer. 2019;26(1):65-71; doi: 10.1007/ s12282-018-0889-X.

38. Odynets T, Briskin Y, Zakharina I, Yefremova A. Impact of a 12-week water program on the respiratory function in breast cancer survivors. Adv Rehabil. 2019;33(2):5-11; doi: 10.5114/areh.2019.85018. 